Working Paper/Document de travail 2014-10

\title{
Macroeconomic Experiences and Risk Taking of Euro Area Households
}

by Miguel Ampudia and Michael Ehrmann 
Bank of Canada Working Paper 2014-10

March 2014

\title{
Macroeconomic Experiences and Risk Taking of Euro Area Households
}

by

\author{
Miguel Ampudia $^{1}$ and Michael Ehrmann ${ }^{2}$ \\ ${ }^{1}$ European Central Bank \\ miguel.ampudia@ecb.europa.eu \\ 2International Economic Analysis Department \\ Bank of Canada \\ Ottawa, Ontario, Canada K1A 0G9 \\ mehrmann@bankofcanada.ca
}

Bank of Canada working papers are theoretical or empirical works-in-progress on subjects in economics and finance. The views expressed in this paper are those of the authors.

No responsibility for them should be attributed to the Bank of Canada, the European Central Bank, or the Eurosystem Household Finance and Consumption Network. 


\section{Acknowledgements}

This paper uses data from the Eurosystem Household Finance and Consumption Survey. We are grateful to Ulrike Malmendier and Stefan Nagel for making their econometric code available, Tetti Tzamourani for help with some data, and thank Dimitris Christelis, Carlos García de Andoain, Dimitris Georgarakos, Nathanael Vellekoop and participants at seminars at the ECB, the Deutsche Bundesbank, the Household Finance and Consumption Network, the Bank of Canada, the ECB conference on Household Finance and Consumption, and the Norges Bank workshop on household finance for useful comments. 


\begin{abstract}
This paper studies to what extent the experiences of households shape their willingness to take financial risks. It follows the methodology of Malmendier and Nagel (2011) and applies it to a novel data set on household finances covering euro area households. We show that experienced stock market returns matter in a statistically significant and economically substantial fashion: better experiences increase the financial risk households are willing to take as well as stock market participation along the intensive and the extensive margin. We find that more distant experiences receive a somewhat lower (but still substantial) weight than the corresponding findings suggest for the United States. Furthermore, there are additional effects stemming from the experience of extreme stock market downturns. Households in countries that witnessed a particularly severe 2008 stock market crash give substantially more weight to the most recent experience, suggesting that in these countries an even more pronounced underinvestment in the stock market should be expected in the years to come. The evidence highlights the relevance of personal experiences for household behavior.
\end{abstract}

JEL classification: D03, D14, D83, G11

Bank classification: Sectoral balance sheet

\title{
Résumé
}

Dans leur étude, Ampudia et Ehrmann cherchent à établir dans quelle mesure les expériences des ménages déterminent leur propension à prendre des risques financiers. Ils reprennent la méthode employée par Malmendier et Nagel (2011) et l'appliquent à un nouvel ensemble de données sur la situation financière des ménages de la zone euro. Ils montrent que les rendements enregistrés sur les marchés boursiers influent sur le comportement des ménages de manière statistiquement et économiquement significative, tant à la marge intensive qu'à la marge extensive, les ménages étant d'autant plus enclins à prendre des risques financiers et à participer aux marchés boursiers que leurs expériences antérieures ont été favorables. Les auteurs constatent que les expériences les plus éloignées dans le temps revêtent une importance légèrement moins marquée (mais néanmoins considérable) que ce que suggèrent les analyses analogues concernant les ÉtatsUnis. S'ajoutent à cela d'autres effets d'expérience liés au fait d'avoir été témoins d'effondrements des marchés boursiers. Ainsi, les ménages des pays qui ont connu une crise boursière particulièrement aigüe en 2008 accordent un poids nettement plus élevé à l'expérience la plus récente, ce qui donne à penser que le déficit de détention d'actions de ces ménages pourrait être encore plus prononcé dans les années à venir. Les résultats de cette étude soulignent le rôle des expériences personnelles dans le comportement des ménages.

Classification JEL : D03, D14, D83, G11

Classification de la Banque : Bilan sectoriel 


\section{Non-technical summary}

This paper studies to what extent the experiences of households shape their willingness to take financial risks, their inclination to participate in stock markets and the amounts that they are willing to invest in stocks. It applies the approach developed by Malmendier and Nagel (2011) and extends the evidence to the euro area, using the Eurosystem Household Finance and Consumption Survey, a novel data set on household finances covering more than 58,000 households in eleven different countries of the euro area.

The data show considerable variation in the experienced stock market returns, stock market participation and the invested amounts both within and across countries. Our estimates show that experienced stock market returns exert statistically significant and economically substantial effects on households' self-assessed willingness to take financial risks and on portfolio decisions, even if we find that more distant experiences receive a somewhat lower (but still substantial) weight than the corresponding findings for the United States. This evidence adds to the literature on time variations in the willingness of households to take financial risks and its determinants, as well as on the factors that shape households' portfolio decisions, emphasizing the importance of personal experiences for economic behavior.

The paper then tests whether the experience of extreme stock market downturns also has a bearing on risk taking and stock market participation. Here as well, the effects are substantial and - importantly come on top of the experienced average stock market returns.

These findings have important policy implications. Households are known to be generally underinvested in the stock market (and even more so in Europe than in the United States), which influences their wealth accumulation. This is especially important in light of the fact that they have been made more and more responsible for their own finances after retirement. In particular, the young and households in countries where the stock market crash in 2008 was very severe tend to give substantially more weight to the recent past when forming their participation decision. This, in turn, implies an even more pronounced underinvestment in stocks among these European households in times to come. Policy-makers should monitor developments carefully, and possibly consider policies to encourage stock market participation among the most affected groups. 


\section{Introduction}

There is ample evidence that the willingness of economic agents to take financial risks has decreased in the course of the global financial crisis. Such a pattern has been found for financial markets (Bekaert and Hoerova 2013), banks (Bassett et al. 2012) and households (Guiso, Sapienza and Zingales 2013). It can therefore be assumed that the willingness to take financial risks varies over time, and depends on the experiences that economic agents have undergone.

Beyond the immediate reaction to adverse events, a recent paper by Malmendier and Nagel (2011) has shown that U.S. households' risk taking is furthermore affected by their experiences over longer time spans: households that have experienced higher real stock market returns over their lifetime tend to be more willing to take financial risks, have a higher propensity to hold stocks and hold larger amounts of stocks.

Personal experiences shape economic behavior in a variety of ways. Having experienced higher inflation, for instance, tends to lower happiness (Blanchflower 2007), increase inflation expectations (Lombardelli and Saleheen 2003; Malmendier and Nagel 2009) and inflation aversion (Ehrmann and Tzamourani 2012). Having grown up during recessionary times matters for preferences: as Alesina and Giuliano (2011) and Giuliano and Spilimbergo (2009) demonstrate, such individuals are more likely to believe that success in life depends more on luck than on effort, and therefore have a more favorable attitude toward redistributional policies. Beyond these macroeconomic factors, experiences of financial market performance also shape agents' behavior: Kaustia and Knüpfer (2008) show that investors are more likely to subscribe to initial public offerings (IPO) on the stock market if their previous IPO investments have performed relatively well, and Choi et al. (2009) suggest that investors overextrapolate from their personal experience when they make their savings decisions.

Of course, the socio-economic background of an individual also affects beliefs and behavior. As reported in Dohmen et al. (2011), the educational background of an individual's parents affects her willingness to take risks. Guiso, Sapienza and Zingales (2004) measure social capital in a region by the electoral turnout and the willingness to donate blood, and find that in high social capital regions in Italy, more households invest in stocks, a pattern that even persists if the individual leaves the region. Finally, using data on German households, Alesina and Fuchs-Schündeln (2007) identify persistent effects of communism on attitudes toward the role of the state in providing social services, insurance or redistribution.

If we accept that individual experiences shape beliefs and behavior, another question is how long these patterns persist. As just mentioned, both the findings in Alesina and Fuchs-Schündeln (2007) and in 
Guiso, Sapienza and Zingales (2004) suggest that there is quite some persistence. Malmendier and Nagel (2011), estimating the impact of financial market experience on risk taking, find that more distant experiences are relatively less important than more recent ones, but that their impact remains noticeable for some decades. Their findings also suggest that young individuals are particularly affected by more recent events. Nakov and Nuño (2014) model this set-up and show that in such an economy, the stock price exhibits stochastic fluctuations around the rational expectations equilibrium due to successive waves of optimism and pessimism.

The current paper uses the methodology developed by Malmendier and Nagel (2011) and applies it to a novel data set on household finances, the Eurosystem Household Finance and Consumption Survey (HFCS). This data set provides information on households' willingness to take financial risks and on participation in financial markets, along with a large number of important control variables, in a harmonized fashion for several countries in the euro area. Our data cover more than 58,000 households in Austria, Belgium, Finland, France, Germany, Greece, Italy, Luxembourg, the Netherlands, Spain and Portugal, i.e. in eleven different countries of the euro area. ${ }^{1}$

The data show considerable variation in the experienced stock market returns both within and across countries. While our measure of the willingness to take financial risks varies relatively little, stock market participation ${ }^{2}$ is widely different across countries, ranging from an average of $3 \%$ in Greece to $22 \%$ in Finland. Among stockholding households, the average share of stocks in total liquid assets is smallest in Germany and the Netherlands with 24\%, and largest in Greece with 38\%. This substantial cross-country variation allows us to identify experience effects separately from age effects despite the fact that only one wave of the survey is currently available.

Our estimates of the effects of lifetime experiences on the willingness to take financial risks and stockholdings among euro area households are fully in line with those identified in Malmendier and Nagel (2011). They are statistically significant and economically substantial. To give just a few examples, households at the 90th percentile of the distribution of experienced stock returns are 7 percentage points less likely to report that they are not willing to take any financial risks than households at the 10 th percentile. With regard to the propensity to hold stocks, a household experiencing a return at the 90th percentile of the distribution is 11 percentage points more likely to be invested in the stock market than a household at the 10 th percentile.

\footnotetext{
1 The HFCS also contains data for Cyprus, Malta, Slovakia and Slovenia. Since we could not obtain sufficiently long historical data for the stock market performance of these countries, we had to discard them from the analysis.

2 Direct stockholdings, or holdings via investments in mutual funds that invest predominantly in equity.
} 
While these estimates closely match those for the United States, our evidence suggests that the effect of experienced stock market returns is less persistent in Europe. Still, also in Europe experiences matter for the willingness to take financial risks and stock market participation for several years.

The paper also tests whether the experience of extreme stock market outcomes has a bearing on stock market participation. Counting the number of times an individual has seen nominal stock market returns decline by more than $20 \%$ in a given year, we once more find substantial effects - for each additional experienced event of this type, the tendency to hold stocks shrinks by 2 percentage points. Over the interdecile range of the experience distribution, this amounts to a 9 percentage point difference in stockholdings.

These findings relate to a previous literature on rare disasters (such as stock market crashes, but also other events like wars) and financial markets. Rietz (1988) and subsequently Barro (2006, 2009) showed that models which take into account the probability of rare disasters can inter alia help to explain the equity premium puzzle. Taking this idea further, Alan (2012) studied whether household portfolio decisions can also be explained by the perceived risk of stock market crashes. While she rejects this hypothesis for the better-educated and wealthy households, there is supportive evidence among the less-educated households.

Dominitz and Manski (2007) have documented that households' expectations of future stock market returns are very heterogeneous, and affect participation and investment patterns. In this paper we argue that, beyond socio-demographic factors, households' experiences of disastrous events are an important factor in shaping their portfolio decisions, possibly via return expectations.

The paper therefore provides further evidence on the relevance of personal experiences for household behavior. These findings have important policy implications. It is a well-known fact that households are generally underinvested in the stock market, a phenomenon that has been dubbed the stockholding puzzle (Haliassos and Bertaut 1995; Campbell 2006). The puzzle is particularly pronounced in Europe, where household stock market participation is even lower than in the United States. This is especially problematic given that households have been made more and more responsible for their own finances after retirement (van Rooij et al. 2011). The findings in the current paper imply that stock market participation will likely be further depressed due to the recent experience of the 2008 stock market crash, suggesting an even more pronounced underinvestment of European households in the stock market in times to come. Policy-makers should therefore monitor developments carefully, and possibly consider policies to encourage stock market participation among the most-affected groups. 
The paper proceeds as follows. Section 2 provides more detail on the underlying data and the econometric methodologies that we employ. Section 3 reports the main findings regarding the effect of individuals' stock market experiences on the willingness to take financial risks and stock market participation, and provides the results of several robustness tests. Section 4 expands the evidence by focusing on the consequences of extreme events. Section 5 concludes.

\section{Data and methodology}

\subsection{Data}

In order to conduct our analysis we will combine household-level data from the HFCS and historical data for stock returns. The HFCS provides ex-ante comparable data for 15 euro area countries (all euro area countries with the exception of Estonia and Ireland). ${ }^{3}$ Since we could not obtain sufficiently long historical data for the stock market performance of Cyprus, Malta, Slovakia and Slovenia, we had to discard them from the analysis. Our data cover more than 58,000 households in 11 euro area countries, namely Austria, Belgium, Finland, France, Germany, Greece, Italy, Luxembourg, the Netherlands, Spain and Portugal.

The HFCS contains information regarding socio-demographic variables, assets, liabilities, income and consumption for a sample of households that is representative both at the national and the euro area level. A set of population weights is provided in order to ensure the representativeness of the sample. All our calculations use these population weights. In section 3.2 we perform unweighted calculations as part of our robustness checks.

Another important feature of the HFCS is that missing observations (i.e. questions that were not answered by the respondent households) are imputed five times - an issue that we will take into account when assessing the statistical significance of our estimates. ${ }^{4}$ The first wave of the HFCS was conducted around 2010, but the reference periods have not been fully harmonized. In particular, the reference period for the Spanish data is 2008/2009, whereas it is 2009 for Greece. We account for these differences when calculating respondents' lifetime experiences. It is important to note, however, that all the households in our sample have lived through the 2008 stock market crash.

\footnotetext{
${ }^{3}$ For more details on the survey, see http://www.ecb.europa.eu/home/html/researcher_hfcn.en.html. The results from the first wave are described in detail in Household Finance and Consumption Network (2013a).

${ }^{4}$ Variables necessary to construct wealth and income aggregates are multiply imputed in each country. Some countries imputed other variables, too. For more information see section 6 and subsection 9.2.7 of Household Finance and Consumption Network (2013b), which describes the most relevant methodological features of the survey, including information on sampling design and weighting.
} 
From the HFCS we are going to retrieve our dependent variables and a set of control variables. In particular, the variables of interest are the household's willingness to take financial risks, whether it participates in the stock market or not, and the share of liquid assets invested in stocks. For determining the household's willingness to take financial risks we use the following question: "Which of the following statements comes closest to describing the amount of financial risk that you (and your husband/wife/partner) are willing to take when you save or make investments?" The respondent can choose one of the following options: 1. Not willing to take any financial risk, 2. Take average financial risks expecting to earn average returns, 3. Take above average financial risks expecting to earn above average returns, or 4. Take substantial financial risks expecting to earn substantial returns. ${ }^{5}$

For stock market participation, we include direct stockholdings as well as investments in mutual funds which invest predominantly in equity. For the share of liquid assets invested in stocks we define liquid assets - in the same way as Household Finance and Consumption Network (2013a) - as the sum of the value of sight accounts, savings accounts, mutual funds, bonds, ownership of non-self-employment private businesses, shares and managed accounts. ${ }^{6}$

In all our model specifications we will control for gender, age, income, education, the stock of liquid assets, whether the reference person ${ }^{7}$ is married, retired, has children or works in the financial sector. The controls follow Malmendier and Nagel (2011), but we added the financial sector affiliation because it might affect the household's tendency to hold stocks and gender, since there is an ample literature documenting that risk attitudes differ between men and women. Finally, we also control for countryfixed effects, given that the literature has found cross-country differences in stock ownership to be primarily linked to differences in economic environments and institutions (Christelis et al. 2013). Furthermore, country-fixed effects take account of possible differences in reporting styles across countries.

\footnotetext{
5 Unfortunately, this question has not been asked in France and Finland. Also, it has not been imputed for all countries, which somewhat restricts the available sample size. Note that we changed the ordering of this variable relative to the way it is measured in the HFCS to match the measurement in Malmendier and Nagel (2011). Accordingly, high values in the original HFCS data set correspond to low values for our variable, and vice versa.

${ }^{6}$ Malmendier and Nagel (2011) also include stocks held in retirement accounts, a variable that is not available for the HFCS. In the robustness section, we will include households that have invested in voluntary pension schemes to get closer to the definition of Malmendier and Nagel (2011).

7 Throughout the paper, "household" and "reference person" should be seen as interchangeable concepts. For example, when we talk about the age of the household it is understood that we are referring to the age of the reference person. The household reference person is chosen according to the international standards of the so-called Canberra Group (UNECE 2011). This definition uses the following sequential steps to determine a unique reference person in the household: (i) household type, (ii) the person with the highest income, (iii) the eldest person.
} 
In order to construct the stock market experiences which the households in our sample have lived through, we use long-term historical time series obtained from Global Financial Data. We use real stock returns (deflated with consumer prices) from 1930 until the year prior to the survey. Since the data do not go back further in time than 1930 (1932 in Portugal), we treat all households born before 1930 as if they were born in 1930 (1932 in Portugal). ${ }^{8}$

We furthermore generate a variable that measures how often a household has experienced a substantial drop in stock prices, which we define as an annual return of below $-20 \%$. This threshold coincides roughly with a one-standard-deviation event, and it covers around $10 \%$ of our year-country observations. Such a decline could occur due to a genuine stock market crash or, alternatively, through a sustained but more gradual decline over the course of a year. Since our data are annual, we cannot distinguish between the two. Of course, we will subject the results to a robustness test where the definition of a stock price drop is altered, to an annual return of below $-40 \%$, which roughly amounts to a 1.7 -standard-deviation event, and covers around $2.5 \%$ of our year-country observations. Note that we base this variable on nominal returns, whereas the overall stock market experiences were calculated using real returns. The reason is that for smaller movements in the stock market, what matters for consumers is the real return they can make with their investment, whereas stock market crashes are typically defined using nominal returns. A robustness test using real returns to define crashes does not alter our results.

\subsection{Methodology}

We are interested in studying the effect of past experiences on the willingness to take financial risks, and the portfolio-choice decisions of households. Following Malmendier and Nagel (2011), we synthesize the lifetime experienced returns of a household using a weighted average of the annual returns conditional on a weighting parameter $\lambda$. The weighting scheme is flexible enough to allow households to give either higher or lower weights to more recently experienced returns. In particular, for each household $i$ in country $c$, the experienced return is constructed as follows:

$$
A_{i c}(\lambda)=\sum_{k=1}^{a g e_{i}-1} w_{i}(k, \lambda) R_{T-k}^{c}
$$

\footnotetext{
8 This affects 3,636 households. Dropping them from the sample does not change the results in any relevant manner - as we will see, experiences before 1930 would anyway get a negligible weight in determining household behavior in current times. For Greece, Global Financial Data extends back only to 1953, but we were able to expand the series back to 1930 using data provided to us by the Bank of Greece.
} 


$$
w_{i}(k, \lambda)=\frac{\left(a g e_{i}-k\right)^{\lambda}}{\sum_{k=1}^{a g e_{i}-1}\left(a^{2} e_{i}-k\right)^{\lambda}}
$$

$R_{T-k}^{c}$ denotes the stock market return in year $T-k$ (where $T$ is the reference period of the survey) in country $c$. The weights $w_{i}(k, \lambda)$ depend on the age of the household and a weighting parameter $\lambda$ which determines the shape of the weighting function (in particular, whether the slope is positive, negative or flat), and the steepness of the slope.

To understand the form of the weighting function, Figure 1 depicts possible weights for the example of a 50 -year-old household, using different values of $\lambda:-0.2$, which corresponds to an increasing weighting function (where the distant past matters more than the recent past); 1, which implies linearly decreasing weights; and 5, a concavely decreasing weighting function. Generally, a negative $\lambda$ implies that the household places a larger weight on more distant experiences, whereas a positive $\lambda$ indicates that returns from the recent past are given a larger weight. As $\lambda$ increases, the effect of past returns fades away more quickly and recent returns are given a relatively larger weight.

Figure 1 here

When calculating lifetime experiences in this manner, we impose a number of assumptions. First, we assume that the relevant horizon extends back to the year of birth. This assumption turns out not to be critical, as we will show by varying the start of the relevant horizon, once to include 10 years prior to birth, and once to start 10 years after birth. A second assumption is that all households "experience" stock market returns, whether they are actually holding stocks or not. Third, we assume that it is the national stock market returns that matter, and thereby implicitly that the reference person did not live abroad or experienced stock market returns in another country by some other means, e.g. by holding an internationally diversified portfolio. While country size might be a relevant factor in this, we think of the latter as a realistic assumption due to the well-known home bias in portfolios, and will subject the former to a robustness test by excluding all households that were not born in the country of residence.

We are going to estimate $\lambda$ from the data. In general, our regression models will have the following form:

$$
y_{i c}=\alpha_{c}+\beta A_{i c}(\lambda)+\delta x_{i c}+\varepsilon_{i c}
$$

where $y_{i c}$ denotes the measure for the willingness to take financial risks, the variable indicating whether a household participates in the stock markets, or the share of stocks in liquid assets. $\alpha_{c}$ are the countryfixed effects, $x_{i c}$ the various control variables and $\varepsilon_{i c}$ a residual. Since $A_{i c}(\lambda)$ is a non-linear term, we have to use non-linear estimation techniques, irrespective of the remaining model specification. 
Note that this model identifies experience effects via the variation of experiences over age and across countries. In the paper by Malmendier and Nagel (2011), identification was achieved by using several waves of the U.S. Survey of Consumer Finances (SCF), such that experiences vary over age and across waves. In other words, equation (3) simply substitutes their time subscript with a country subscript. The idea of identification is, however, equivalent.

We first look at the effect of experiences on the willingness to take financial risks. Since the dependent variable takes four values, we use an ordered probit model for the estimation. When our dependent variable is the stock market participation decision we use a probit model, and when we look at the share of the portfolio invested in stocks we use a Tobit model.

When the experienced return is our independent variable of interest, we first identify an initial value for $\lambda$ by estimating the model on a tight grid of given lambdas. The value for $\lambda$ that achieves the highest likelihood is then used as the initial value in the non-linear estimation. This procedure ensures avoiding local maximums, apart from substantially reducing computation time.

Our other independent variable of interest is the number of stock market crashes experienced. For the model specifications dealing with this independent variable we do not include a weighting function, thereby implicitly assuming that the effects of crashes persist and accumulate. Therefore, it is important to allow for a non-linear effect, which we do by using a quadratic term, such that the model is estimated as follows:

$$
y_{i c}=\alpha_{c}+\beta_{1} S_{i c}+\beta_{2} S_{i c}^{2}+\delta x_{i c}+\varepsilon_{i c}
$$

All variables are described as in equation (3), and $S_{i c}$ is the number of experienced stock market crashes.

As with Malmendier and Nagel (2011), we use a weighted estimation to account for the fact that the survey does not always represent the same fraction of the overall population across countries. Our weights readjust each observation to reflect their relative importance for the euro area as a whole. In so doing, we also follow Faiella (2010) and Magee et al. (1998), who recommend the use of weights for two similar surveys, namely Italy's Survey on Household Income and Wealth and Canada's SCF. They argue that, in surveys with complex survey design, the use of weights protects against the omission of relevant information, which otherwise would have to be modelled explicitly by incorporating all available geographic and operational variables that determine sampling rates. Another reason for using weights is due to the possibility of endogenous sampling (Solon et al. 2013), since the HFCS oversamples wealthy households, and given that stock market participation varies with wealth. 


\subsection{Descriptive statistics}

Table 1 provides descriptive statistics for households' willingness to take financial risks, stock market participation and the share of liquid assets invested in stocks. The willingness to take financial risks shows little variation, both within and across countries. In eight of the nine countries where this variable is available (remember that this question was not asked in Finland and France), the median household reports the lowest willingness to take financial risks (coded as 1). Italy is the only exception, with a median of 2 . The mean figure is 1.4 for the euro area as a whole, and it varies from 1.1 in Portugal to 1.7 in Italy. Overall, these results are not very different from the mean value of 1.8 that was found for U.S. households in Malmendier and Nagel (2011). Still, as we will see, despite the low variability of this variable, it is sufficient to estimate meaningful results.

Table 1 here

Participation rates in stock markets are very low (see the second panel of Table 1); only 13\% of households report some stockholdings. Importantly, however, there is considerable variation across countries, with participation rates ranging from 3\% in Greece to 22\% in Finland. Conditional on stockmarket participation, euro area households keep 30\% of their liquid assets in stocks. But this figure, reported in the third panel of Table 1, also varies across countries. The mean ranges from $24 \%$ in Germany and the Netherlands to $38 \%$ in Greece. Interestingly, there is also a substantial amount of variation within countries. There are many households with very small amounts of stocks in their portfolios, as shown by the small numbers for the 10th percentile, whereas the 90th-percentile household in several countries holds substantial amounts of stocks (e.g. above 80\% in Finland, Greece, Luxembourg and Spain). ${ }^{9}$ Taken together, the low participation rates and the small fraction of assets that are held in stocks suggest that households account for a very small fraction of stock market capitalization, thereby making concerns about reverse causality (whereby changes in households' willingness to take financial risks affect stockholdings and thereby stock market returns) less relevant.

Table 2 here

Table 2 provides a first look at our main explanatory variables. In the upper panel, we report summary statistics for the experienced stock market returns of households, $A_{i c}$. They are calculated using a weighting factor of $\lambda=4.5$, which is close to the estimates that we will report below. There is substantial

\footnotetext{
9 The dependent variable in our regressions will not be conditional on stockholdings, i.e. we include households that do not hold stocks in our sample.
} 
variability in the experiences across and within countries: they range from $4 \%$ in Italy to $13 \%$ in Finland. The variation within countries is largest in Greece, where the 10th percentile of the return distribution is $3 \%$ and the 90 th percentile is $13 \%$.

These figures suggest that there is substantial variability in real stock market returns. Importantly, this variation is largely due to differences in nominal returns, and only to a small extent to differences in inflation rates. Table 3 shows the correlations between each country's nominal stock market returns for the whole sample from 1930 to 2010. Correlations are rarely higher than 0.5, and in a few cases they even take negative values.

Table 3 here

When we examine the number of protracted stock market declines or genuine stock market crashes that households have experienced (reported in the second panel of Table 2), we once more find substantial variability across and within countries. The mean number of stock market downturns that households have experienced ranges from 3.4 in Austria to 11.6 in Portugal. In many countries, the difference between the 10th and 90th percentiles of the distribution is as large as, or even larger than, six events.

To summarize, the descriptive statistics show that there is substantial variation in our dependent and explanatory variables both across and within countries. We next study how an individual's experience affects the willingness to take financial risks and stock market participation.

\section{The effect of experiences on the willingness to take financial risks and stock market participation}

\subsection{Benchmark results}

Table 4 provides the first set of results. It reports the estimated coefficients of the ordered probit model, explaining the willingness to take financial risks, as well as the average marginal effects for each category. Note that the standard errors take account of the multiply imputed nature of the data, thereby properly reflecting the uncertainty of the imputed values. Several of the control variables are relevant. Higher income and a higher stock of liquid assets tend to decrease the willingness to take financial risks, even though for both variables there are important non-linearities, as suggested by the statistical significance of the squared terms. The retired are somewhat less willing to take financial risks than other households, an effect that is found on top of a decreasing willingness to take financial risks with age (the latter has already been documented in the literature, see Dohmen et al. (2011)). Education also 
seems to matter, with higher levels of education being associated with a higher willingness to take financial risks. As is well known from the literature (see, inter alia Borghans et al. (2009)), males tend to be more willing to take risks than females, a pattern that is also observed in our data. Our control for respondents who are working in the financial sector is highly statistically significant, and suggests that these individuals are more willing to take financial risks (the average marginal effect suggests that they are 7.5 percentage points less likely to be unwilling to take any financial risk, which makes the financial sector dummy, together with gender, the most influential sociodemographic factor). Finally, the countryfixed effects are estimated to be highly relevant, with Italians being more willing to take financial risks than Germans, and respondents in Belgium, Luxembourg, the Netherlands, Portugal and Spain reporting a lower willingness to take financial risks than their counterparts in Germany.

Table 4 here

Moving to the two main parameters of interest, $\beta$ and $\lambda$, both are statistically significant and have the expected sign. The weighting parameter $\lambda$ is estimated to be 3.9, considerably larger than Malmendier and Nagel's (2011) corresponding estimate of 1.4 for the United States. This points to a higher decay factor in Europe. To take the example of a 30-year-old individual, a European would assign a weight of $15.6 \%$ to the previous year's experience, whereas a U.S. household would give it a weight of only $7.9 \%$. Despite this large initial difference, memories are rather persistent also for the European household, who is estimated to assign a weight of $3.7 \%$ to experiences undergone 10 years ago (whereas the number in the United States amounts to 4.7\%). Taking the example of an individual with a longer life history, the relevance of past experience becomes even more apparent: according to our estimates, a 50year-old person would weigh the most recent year with 9.5\%, and the experience undergone a decade ago with 4.3\%. Even the stock market returns experienced 20 years ago would enter the weighting function with $1.4 \%$.

As expected, the coefficient estimate for $\beta$ indicates that higher experienced returns tend to increase the willingness to take financial risks. The average marginal effects show that an increase in experienced returns by 1 percentage point makes households 1.4 percentage points more likely to declare that they are not willing to take any financial risk. Comparing the average of the fitted probabilities at the 90th percentile of the distribution of experienced returns with the average of the fitted probabilities at the 10th percentile yields a difference of 6.7 percentage points. This effect is of substantial magnitude (it is 
similar to that found for financial sector employees or males), and is comparable to the 10.3 percentage points that were identified by Malmendier and Nagel (2011) for the United States. ${ }^{10}$

The next question is whether there are any repercussions on actual stock market participation. Table 5 reports the results from the probit model explaining the households' participation decision. Once more, a number of control variables appear to be significant. Participation is found to increase for males as well as for households with high liquid assets, high education and working in the financial sector. Compared to Germany, stock market participation is higher in Belgium and France, and lower in Austria, Luxembourg and Portugal.

\section{Table 5 here}

As before, parameter $\lambda$ is significantly estimated, and at 5.2 is larger than what was found for the United States (1.3). Once again, however, the parameter still implies that memories persist - for the 30-year old, experiences undergone 10 years ago receive a weight of $2.8 \%$; for a 50 -year old, it amounts to $4.1 \%$.

Parameter $\beta$ is statistically significant. Judging from the marginal effect and the interdecile range reported in Table 5, it is apparent that the magnitude is economically important - a one-percentagepoint higher experienced stock return increases the propensity to hold stocks by 2 percentage points, and the difference in stock market participation along the interdecile range of the stock market experiences amounts to 11 percentage points, which is rather close to the 10 percentage points estimated by Malmendier and Nagel (2011), and again similar to the effect of working in the financial sector.

The third test is conducted on the share of liquid assets invested in stocks. The results, reported in Table 6, are based on a Tobit model, such that the coefficients are now directly interpretable. ${ }^{11}$ The share of stocks in the liquid assets held by financial sector employees is 26 percentage points higher than among other households. Furthermore, the share of stocks rises with the stock of liquid assets and education (college graduates have a 19-percentage-point higher share of stock investments than households with less than a high school degree).

Table 6 here

\footnotetext{
10 The difference between the 90th and the 10th percentile is broadly comparable between the euro area and the United States. At the respectively estimated $\lambda$, it amounts to $(11.9 \%-6.2 \%=5.7 \%)$ for the United States, and to $(9.3 \%-4.2 \%=5.1 \%)$ in the euro area.

11 Non-linear least-squares models for the shares conditional on stockholdings (i.e. excluding households with a share of zero) did not lead to any significant results. This suggests that households' experiences mainly affect their participation decision, rather than the amounts held.
} 
As previously, we estimate statistically significant parameters for $\lambda$ and $\beta .^{12}$ Comparing households along the interdecile range suggests that those at the 90th percentile of the distribution invest 5 percentage points more in stocks than those at the 10th percentile (once more, these numbers are comparable with those for the United States).

\subsection{Robustness tests}

We have subjected our results to a large number of robustness tests. First, analogous with Malmendier and Nagel (2011), we have also tested whether similar results can be obtained for bond market experiences and their effects on bond holdings. ${ }^{13}$ Judging from the descriptive statistics, there is much less variability in bond market returns than in stock market returns. In large part, this is due to the near-complete convergence of government bond yields in the euro area between 1999 and 2010 (Ehrmann et al. 2011). Accordingly, we expect our results to be weaker than for stockholdings. Comparing the estimates for $\beta$ and $\lambda$ (reported in Table 7) between the benchmark model in row (1) and those for bond markets in row (2), it is apparent that we estimate a rather similar coefficient for $\lambda$, at 3.99 (compared to 5.24 for stocks). Parameter $\beta$, in contrast, is only marginally significant for the bond market participation decision.

Table 7 here

The remaining robustness tests, reported in rows (3) to (16) of Table 7, go back to explaining the stock market participation decision as a function of stock market experiences. The first of these allows for an additional effect of experienced stock market volatility. For that purpose, we added the experienced stock market volatility (calculated as the weighted standard deviation of the respondents' lifetime experience, using the previously estimated $\lambda$ as a weighting parameter) to the benchmark regression. As can be seen from row (3) of Table 7, our results remain robust. While the experienced volatility itself lowers stock market participation in a statistically significant manner (a result that has also been found for the United States in Appendino (2013)), the effects of the experienced returns and the weighting parameters are basically unaltered.

\footnotetext{
12 Our estimates of $\lambda$ are quite different for the effect of experiences on households' willingness to take financial risks, stock market participation and the share of stocks in liquid assets, whereas they are rather similar across these three models in Malmendier and Nagel (2011). We do not see any reason why they would need to be similar across the three specifications, given that they measure very different concepts, which might be affected differently by previous experiences.

13 Bond returns are calculated for long-term bonds. Since bond returns for Luxembourg are not available prior to 1947, we exclude Luxemburgish households born before 1947. The bond holdings are defined in analogy to the stockholdings as directly held bonds or investments in mutual funds that themselves predominantly invest in bonds.
} 
Results are also stable for the robustness test in row (4), where we broadened the definition of stockholdings to include not only direct stockholdings and investments in mutual funds that themselves predominantly invest in stocks, but also investments in voluntary pension plans. This change in definition raises the stock market participation rate of euro area households from $13 \%$ to $39 \%$. Still, all results go through.

For the subsequent robustness test, we reran our estimations without using population weights. Here, the quantitative results change, but qualitatively remain robust. The experienced stock returns exert a smaller effect on stockholdings, and the weighting parameter is substantially larger, indicating that the more recent experiences matter more. Where do these differences come from? The new set of results treats each observation equally, whereas, before, observations reflected the countries' population shares in the euro area. In Table 1, it is evident that countries such as France and, in particular, Finland receive much more prominence in the new estimation (since they have by far the largest samples in the survey, exceeding their population share), whereas the relevance of, for instance, German observations diminishes when using an unweighted regression (since the approximately 3,500 households representing Germany in the HFCS make up 6\% of the overall sample, whereas the German households effectively account for around 29\% of the euro area household population). The change in coefficients does therefore point to differences in the economic significance of the effects across the various countries. As we will see below, these differences are tightly related to how severely the countries were hit by the 2008 stock market crash. Finland and France were among the more strongly affected countries compared to Germany, and in the countries with the severest stock market crashes, the most recent experience receives a rather strong weight.

The fifth robustness test includes an additional regressor, namely the bond returns that households have experienced over their lifetimes (keeping the weighting parameter from the robustness test provided in row (2), i.e. when explaining bond market participation with experienced bond returns). Experienced bond returns themselves exert a significant effect on stockholdings. As one would expect, this somewhat diminishes the quantitative importance of the experienced stock returns, but does not change the picture qualitatively (see row (6) of Table 7). The next two rows of Table 7 show how our results change if we vary the experience horizon of respondents, by either including 10 years prior to birth, or starting 10 years after birth. In both cases, the magnitudes of our parameters change somewhat, but without affecting the overall results in any meaningful manner.

In row (9), we also show that including the willingness to take financial risks as an additional regressor has barely any impact on the results. While not a definite test, this finding suggests that the effect of experiences on stockholdings works primarily via influencing beliefs rather than preferences, as also 
argued by Malmendier and Nagel (2011). In row (10), we add the level of a household's real asset holdings, since these could be seen as a substitute to stockholdings. We find our results to be unaltered. Row (11) includes year-of-birth dummies as control variables and it shows that our results are not driven by cohort effects.

Row (12) of the table shows the result for a regression in which we exclude immigrants from the sample. Specifically, we drop all households who were born in a country different from the one they have been interviewed in, since immigrants are more likely to have been exposed to stock market returns in countries other than their country of residence. We exclude France, Spain and the Netherlands, since we do not have information on the country of birth of the household for these households. Again, all our results hold. ${ }^{14}$ The subsequent robustness test, reported in row (13), clusters standard errors by country. All results go through.

Finally, as a way to test for possible spurious correlations, we run a placebo experiment. ${ }^{15}$ For that purpose, we randomly assign a different nationality to each cohort in a given country (for instance, all 35-year-old households in France are randomly allocated a nationality other than the French one, all 36year-old French households are independently assigned a random nationality, etc.). With this placebo allocation of nationalities, we then rerun our estimations. As can be seen from row (14) of Table 7, the pseudo-lifetime experiences are not found to affect stock market participation: they are neither statistically significant nor economically large.

\section{Any difference for extreme events?}

The experience of the stock market crash in 2008 is still vividly remembered by stock market participants. Many of these have lost substantial amounts of wealth, which in turn has been shown to affect risk taking (Necker and Ziegelmeyer 2013). A natural question is therefore whether extreme events such as stock market crashes influence attitudes and behaviors in a more persistent manner than less-extreme experiences. Related evidence supporting this hypothesis is provided by Ehrmann and Tzamourani (2012), who show that the effect of experienced inflation on inflation aversion typically fades away, whereas memories of hyperinflation tend to stay in people's minds and affect attitudes in a much more persistent manner.

\footnotetext{
${ }^{14}$ As can be seen in Table 7, the coefficients for this robustness check differ from the ones in the baseline specification, but this is due to the different samples used. When we run the baseline specification excluding France, Spain and the Netherlands, the results are almost identical to those of row (10) in Table 7.

${ }^{15}$ We are grateful to Dimitris Georgarakos for suggesting this idea.
} 
While of interest on their own, studying the effect of crashes on households also provides another robustness test of the previous results. We had assumed that households "experience" regular stock market developments, regardless of whether they actually hold stocks. For the current estimations, we can relax this assumption partially and only need to assume that households take note of stock market crashes, which seems a rather uncontroversial assumption.

\section{Table 8 here}

Table 8 reports the estimates of the effect of stock market crashes - or protracted stock market declines - on the willingness to take financial risks. Note that this specification does not contain a $\lambda$ factor, i.e. we simply count the number of such experiences the individuals have made over their lifetimes and enter this as an explanatory variable (thereby already assuming that these experiences remain an important factor in influencing the willingness to take financial risks and stock market participation, and that they are additive). The results indicate that for each such additional experience, the propensity not to take any financial risks increases by 1 percentage point. Looking at the interdecile range, this amounts to a difference of 4.4 percentage points. While this number might not sound overly large, it is important to note that many of the stock market declines were experienced a considerable time ago (more than $70 \%$ before 1990, 45\% before 1970). These numbers take into account a non-linearity in the effects: the squared number of experienced events enters with a significant positive sign, suggesting that with increasing numbers of experienced stock market downturns the decrease in the willingness to take financial risks becomes less pronounced.

The propensity to hold stocks is affected in a similar fashion, as can be seen from Table 9. Here, the fitted probabilities along the interdecile range generate a difference in stockholding propensities of $9.1 \%$, i.e. nearly as much as the differences generated by the interdecile range in the experience of stock market returns themselves. In contrast, the share of liquid assets invested in stocks does not seem to be affected by the number of experienced stock market downturns (given that the parameter estimates reported in Table 10 are statistically insignificant, and the difference across the interdecile range is small), suggesting that the effect is more one of whether to hold stocks than how much to hold in stocks.

\section{Tables 9 and 10 here}

We extended the analysis in several dimensions, focusing in particular on stock market participation, in line with the literature on rare events and household finance. These extensions, as well as a number of robustness tests, are reported in Table 11 - which repeats the average marginal effect obtained in the benchmark estimations in row (1). First, we combined regression models (3) and (4) by including both $S_{i c}$, the number of experienced stock market downturns (as well as its squared value), and $A_{i c}$, the 
experienced returns. The results show that the effect of experienced returns and the weighting parameter $\lambda$ barely change in the new specification compared to the previous results, whereas the number of experienced downturns (reported in row (2) of Table 11) exerts an additional effect on the participation decision.

Table 11 here

We have furthermore extended equation (4) by allowing for a separate effect of stock market booms (which we defined in analogy to downturns as nominal annual returns in excess of $+20 \%$ ). We find that booms are much less relevant than downturns (the coefficient, not shown in the table, is insignificant). Even though one might expect that more households are inclined to invest in the stock market during boom times (and stay invested subsequently), this effect is not evident in the data. In contrast, the coefficient estimates for the effect of downturns remain basically unaltered (row (3) of Table 11).

Given that the survey was conducted just after the 2008 stock market crash, all households in our sample have experienced at least one crash. To get at the importance of the most recent crash on household portfolios, we made use of the fact that the 2008 crash was hitting the various countries in rather different ways. Based on the analysis in Bekaert et al. (2013), we split the countries into those that were affected by the crisis somewhat less severely (namely Austria, Belgium, Germany, Spain, Luxembourg and the Netherlands, which on average saw their stock markets decline by 36\%), and those where stock markets were hit particularly badly (i.e. Finland, France, Greece, Italy and Portugal, with an average drop of 52\%), and then repeated the analysis of section 3 separately for each country group. The results are provided as the two bottom rows of Table 7 . There are remarkable differences across the two groups: whereas our results are robust for the countries that got hit less badly, the weighting parameter $\lambda$ in the more strongly affected countries is estimated at 10.9. This implies that, in these countries, the experience of the recent crisis overshadows the earlier experiences, which receive a much smaller weight in households' decisions. It can help to explain why $\lambda$ is estimated to be so much higher in Europe than in the United States (given that Malmendier and Nagel (2011) used several waves of the SCF, therefore also covering the years prior to the recent crisis).

Finally, we subjected our findings in this section to a number of robustness tests, by (i) changing the definition of a downturn to cases where annual nominal stock returns were below $-40 \%$ (moving us from $10 \%$ to around $2.5 \%$ of the year-country observations), (ii) including voluntary pension plans in our definition of stockholdings, (iii) estimating the models without using population weights, (iv) including the household's willingness to take financial risks as an additional regressor, (v) adding the level of real asset holdings, (vi) including year-of-birth dummies as control variables, (vii) excluding 
immigrants from the sample and (viii) clustering standard errors by country. Results are reported in rows (4) to (11) of Table 11. This table shows that for more extreme events, the effects are substantially larger, as well as when we broaden the definition of stockholdings to include voluntary pension plans. The average marginal effect becomes insignificant if we run the regression unweighted and if we drop the immigrants from the sample (which also implies dropping France, Spain and the Netherlands because of data availability).

In addition, we conduct a placebo experiment analogous to the one explained in the previous section (row (12)). Once we randomly assign the number of crashes experienced, the effect of this placebo variable is not significant. This supports the validity of our results.

\section{Conclusions}

This paper has studied to what extent the experiences of households shape their willingness to take financial risks, their inclination to participate in stock markets and the amounts that they invest in stocks. It has applied the approach developed by Malmendier and Nagel (2011) and extended the evidence to Europe, using the Eurosystem Household Finance and Consumption Survey, a novel data set on household finances covering more than 58,000 households in eleven different countries of the euro area.

The data show considerable variation in the experienced stock market returns, stock market participation and the invested amounts both within and across countries. Our estimates show that experienced stock market returns exert statistically significant and economically substantial effects on households' willingness to take financial risks and portfolio decisions, even if we find that more distant experiences receive a somewhat lower (but still substantial) weight than the corresponding findings for

the United States. This evidence adds to the literature on time variations in the risk-taking attitudes of households and its determinants, as well as on the factors that shape households' portfolio decisions, emphasizing the importance of personal experiences for the formation of attitudes and economic behavior.

The paper also tested whether the experience of extreme stock market downturns has a bearing on households' willingness to take financial risks and stock market participation. Here as well, the effects are substantial and - importantly - come on top of the experienced average stock market returns. Rietz (1988), Barro (2006, 2009) and Alan (2012) have demonstrated that expectations of rare disasters can help explain financial market behavior and, partially, household decisions. Our evidence suggests that 
households are likely to factor in their own experiences of disastrous events when making their portfolio decisions.

These findings have important policy implications. Households are known to be generally underinvested in the stock market (and more so in Europe than in the United States), especially in light of the fact that they have been made more and more responsible for their own finances after retirement. Particularly, the young and households in countries where the stock market crash in 2008 was very severe tend to give substantially more weight to the recent past when forming their participation decision. This, in turn, implies an even more pronounced underinvestment in stocks among these households in times to come. Policy-makers should monitor developments carefully, and possibly consider policies to encourage stock market participation among the most affected groups. 


\section{References}

Alan, S. (2012). Do Disaster Expectations Explain Household Portfolios? Quantitative Economics 3, 1-28.

Alesina, A. and P. Giuliano (2011). Preferences for Redistribution, in: Bisin, A., Benhabib, J. (Eds.), Handbook of Social Economics. North Holland, Amsterdam, 93-132.

Alesina, A. and N. Fuchs-Schündeln (2007). Goodbye Lenin (or Not?): The Effect of Communism on People. American Economic Review 97(4), 1507-1528.

Appendino, M. (2013). Lifetime Experience of Volatility: A New Determinant of Household Demand for Stocks. Mimeo, Yale University.

Barro, R.J. (2006). Rare Disasters and Asset Markets in the Twentieth Century. Quarterly Journal of Economics 121(3), 823-866.

Barro, R.J. (2009). Rare Disasters, Asset Prices, and Welfare Costs. American Economic Review 99(1), 243-264.

Bassett, W., M. Chosak, J.C. Driscoll and E. Zakrajsek (2012). Changes in Bank Lending Standards and the Macroeconomy. FEDS Paper No. 2012-24, Board of Governors of the Federal Reserve System.

Bekaert, G., M. Ehrmann, M. Fratzscher and A. Mehl (2013). The Global Crisis and Equity Market Contagion. Forthcoming, Journal of Finance.

Bekaert, G. and M. Hoerova (2013). The VIX, the Variance Premium and Stock Market Volatility. NBER Working Paper No. 18995.

Blanchflower, D.G. (2007). Is Unemployment More Costly than Inflation? NBER Working Paper No. 13505.

Borghans, L., B.H.H. Golsteyn, J.J. Heckman and H. Meijers (2009). Gender Differences in Risk Aversion and Ambiguity Aversion, Journal of the European Economic Association, 7(2-3), 649-658.

Campbell, J. (2006). Household Finance. Journal of Finance 61, 1553-1604.

Choi, J.J., D.I. Laibson, B.C. Madrian and A. Metrick (2009). Reinforcement Learning and Savings Behavior. Journal of Finance 64, 2515-2534.

Christelis, D., D. Georgarakos, and M. Haliassos (2013): Differences in Portfolios across Countries: Economic Environment versus Household Characteristics. Review of Economics and Statistics, 95(1), 220-236.

Dohmen, T., A. Falk, D. Huffman, U. Sunde, J. Schupp, and G. G. Wagner (2011). Individual Risk Attitudes: Measurement, Determinants, and Behavioral Consequences. Journal of the European Economic Association 9 (3), 522-550.

Dominitz, J. and C.F. Manski (2007). Expected Equity Returns and Portfolio Choice: Evidence from the Health and Retirement Study. Journal of the European Economic Association 5(2-3), 369-379. 
Ehrmann, M., M. Fratzscher, R. Gürkaynak and E. Swanson (2011). Convergence and Anchoring of Yield Curves in the Euro Area. Review of Economics and Statistics 93, 350-364.

Ehrmann, M. and P. Tzamourani (2012). Memories of High Inflation. European Journal of Political Economy 28(2), 174-191.

Faiella, I. (2010). The Use of Survey Weights in Regression Analysis. Banca d'Italia Working Paper No. 739.

Giuliano, P. and A. Spilimbergo (2009). Growing up in a Recession: Beliefs and the Macroeconomy. NBER Working Paper No. 15321.

Guiso, L., P. Sapienza and L. Zingales (2004). The Role of Social Capital in Financial Development. American Economic Review 94(3), 526-556.

Guiso, L., P. Sapienza and L. Zingales (2013). Time Varying Risk Aversion. NBER Working Paper No. 19284.

Haliassos, M. and C. Bertaut (1995). Why Do So Few Hold Stocks? Economic Journal 105, 1110-1129.

Household Finance and Consumption Network (2013a). The Eurosystem Household Finance and Consumption Survey - Results from the First Wave, ECB Statistics Paper No. 2.

Household Finance and Consumption Network (2013b). The Eurosystem Household Finance and Consumption Survey - Methodological Report for the First Wave, ECB Statistics Paper No. 1.

Kaustia, M. and S. Knüpfer (2008). Do Investors Overweight Personal Experience? Evidence from IPO Subscriptions. Journal of Finance 63(6), 2679-2702.

Lombardelli, C. and J. Saleheen (2003). Public Expectations of UK Inflation. Bank of England Quarterly Bulletin 43, 281-290.

Magee, L., A. Robb and J. Burbidge (1998). On the Use of Sampling Weights When Estimating Regression Models with Survey Data. Journal of Econometrics 84, 251-271.

Malmendier, U. and S. Nagel (2009). Learning from Inflation Experiences. Mimeo, UC Berkeley and Stanford University.

Malmendier, U. and S. Nagel (2011). Depression Babies: Do Macroeconomic Experiences Affect Risk Taking? Quarterly Journal of Economics 126(1), 373-416.

Nakov, A. and G. Nuño (2014). Learning from Experience in the Stock Market. CEPR Discussion Paper No. 9845.

Necker, S. and M. Ziegelmeyer (2013). Risk Taking after the Financial Crisis. Mimeo, University of Freiburg.

Rietz, T.A. (1988). The Equity Risk Premium. A Solution. Journal of Monetary Economics 22, 117-131.

Solon, G., S.J. Haider and J. Woolridge (2013). What are We Weighting For? NBER Working Paper No. 18859. 
United Nations Economic Commission for Europe (UNECE) (2011). Canberra Group Handbook on Household Income Statistics. Second Edition. United Nations.

van Rooij, M., A. Lusardi and R. Alessie (2011). Financial Literacy and Stock Market Participation. Journal of Financial Economics 101(2), 449-472. 
Figure 1: Examples of weighting functions for a 50-year-old household

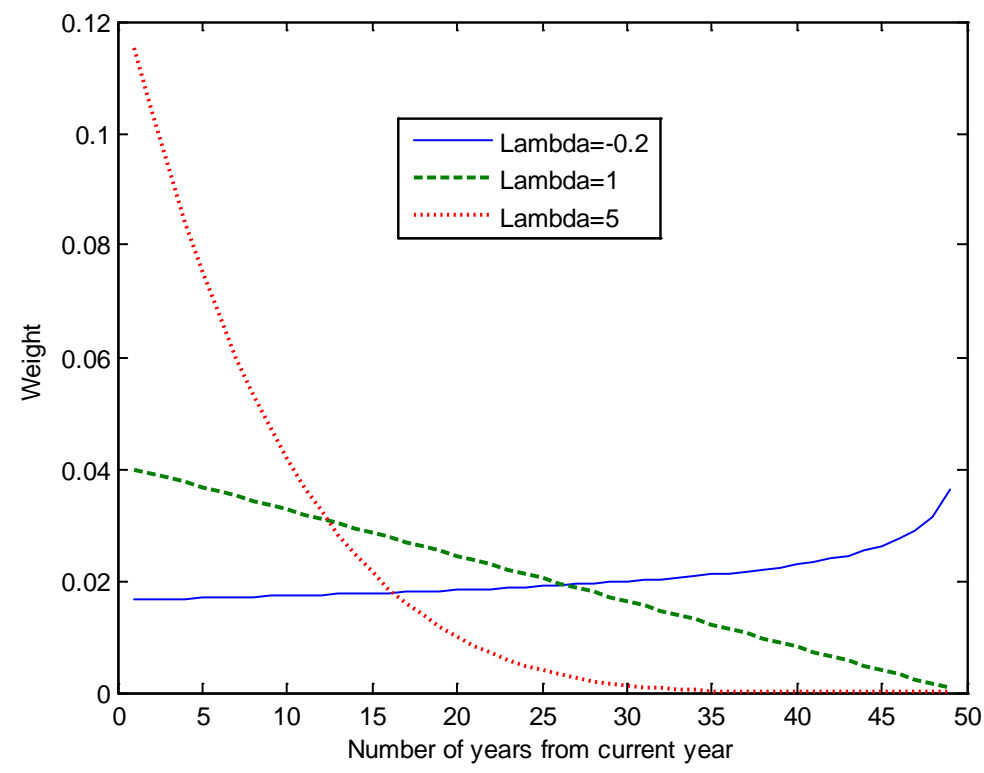

Note: The figure plots weighting functions for a 50-year-old household according to equations (1) and (2), for different values of $\lambda$. 
Table 1: Summary statistics: willingness to take financial risks, stock market participation and the share of liquid assets invested in stocks

\begin{tabular}{|c|c|c|c|c|c|c|}
\hline Country & Mean & Std. Dev. & p10 & Median & p90 & Observations \\
\hline \multicolumn{7}{|c|}{ Willingness to take financial risks } \\
\hline Austria & 1.48 & 0.71 & 1 & 1 & 2 & 2340 \\
\hline Belgium & 1.33 & 0.60 & 1 & 1 & 2 & 2307 \\
\hline Finland & 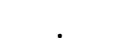 & . & . & . & . & 0 \\
\hline France & 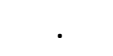 & . & . & . & . & 0 \\
\hline Germany & 1.39 & 0.56 & 1 & 1 & 2 & 3467 \\
\hline Greece & 1.31 & 0.66 & 1 & 1 & 2 & 2971 \\
\hline Italy & 1.70 & 0.79 & 1 & 2 & 3 & 7951 \\
\hline Luxembourg & 1.28 & 0.53 & 1 & 1 & 2 & 950 \\
\hline Netherlands & 1.31 & 0.52 & 1 & 1 & 2 & 1253 \\
\hline Portugal & 1.10 & 0.38 & 1 & 1 & 1 & 4365 \\
\hline Spain & 1.19 & 0.47 & 1 & 1 & 2 & 6197 \\
\hline Euro Area & 1.41 & 0.64 & 1 & 1 & 2 & 31801 \\
\hline \multicolumn{7}{|c|}{ Stock market participation } \\
\hline Austria & 0.08 & 0.28 & 0 & 0 & 0 & 2380 \\
\hline Belgium & 0.20 & 0.40 & 0 & 0 & 1 & 2327 \\
\hline Finland & 0.22 & 0.41 & 0 & 0 & 1 & 10989 \\
\hline France & 0.16 & 0.37 & 0 & 0 & 1 & 15006 \\
\hline Germany & 0.16 & 0.37 & 0 & 0 & 1 & 3565 \\
\hline Greece & 0.03 & 0.17 & 0 & 0 & 0 & 2971 \\
\hline Italy & 0.06 & 0.23 & 0 & 0 & 0 & 7951 \\
\hline Luxembourg & 0.18 & 0.39 & 0 & 0 & 1 & 950 \\
\hline Netherlands & 0.15 & 0.36 & 0 & 0 & 1 & 1301 \\
\hline Portugal & 0.05 & 0.22 & 0 & 0 & 0 & 4404 \\
\hline Spain & 0.11 & 0.31 & 0 & 0 & 1 & 6197 \\
\hline Euro Area & 0.13 & 0.34 & 0 & 0 & 1 & 58041 \\
\hline \multicolumn{7}{|c|}{ Share of liquid assets invested in stock } \\
\hline Austria & 0.28 & 0.26 & 0.02 & 0.22 & 0.71 & 130 \\
\hline Belgium & 0.31 & 0.27 & 0.02 & 0.24 & 0.72 & 425 \\
\hline Finland & 0.34 & 0.30 & 0.03 & 0.23 & 0.84 & 2996 \\
\hline France & 0.33 & 0.28 & 0.03 & 0.25 & 0.79 & 3161 \\
\hline Germany & 0.24 & 0.23 & 0.02 & 0.17 & 0.59 & 648 \\
\hline Greece & 0.38 & 0.32 & 0.05 & 0.29 & 0.91 & 73 \\
\hline Italy & 0.34 & 0.27 & 0.05 & 0.27 & 0.79 & 427 \\
\hline Luxembourg & 0.34 & 0.30 & 0.02 & 0.26 & 0.86 & 123 \\
\hline Netherlands & 0.24 & 0.26 & 0.02 & 0.13 & 0.76 & 170 \\
\hline Portugal & 0.29 & 0.29 & 0.01 & 0.21 & 0.79 & 213 \\
\hline Spain & 0.34 & 0.30 & 0.02 & 0.23 & 0.84 & 1387 \\
\hline Euro Area & 0.30 & 0.27 & 0.02 & 0.21 & 0.76 & 9753 \\
\hline
\end{tabular}

Note: The table shows summary statistics for households' willingness to take financial risks (top panel), for whether or not households hold stocks (middle panel), and for the share of stocks in liquid assets, conditional on stock ownership (bottom panel). Sources: Eurosystem Household Finance and Consumption Survey, own calculations. 
Table 2: Summary statistics: lifetime experiences

\begin{tabular}{|c|c|c|c|c|c|c|}
\hline Country & Mean & Std. Dev. & p10 & Median & p90 & Observations \\
\hline \multicolumn{7}{|c|}{ Experienced average real stock return $(\lambda=4.5)$} \\
\hline Austria & 10.62 & 0.37 & 10.09 & 10.65 & 11.16 & 2380 \\
\hline Belgium & 6.85 & 1.12 & 5.11 & 7.16 & 8.05 & 2327 \\
\hline Finland & 12.95 & 2.81 & 8.28 & 14.07 & 15.57 & 10989 \\
\hline France & 7.48 & 1.26 & 5.44 & 7.83 & 8.84 & 15006 \\
\hline Germany & 8.06 & 0.15 & 7.84 & 8.06 & 8.26 & 3565 \\
\hline Greece & 8.84 & 3.83 & 3.19 & 10.15 & 12.73 & 2971 \\
\hline Italy & 3.86 & 1.39 & 1.93 & 4.16 & 5.38 & 7951 \\
\hline Luxembourg & 10.39 & 0.37 & 9.82 & 10.41 & 10.86 & 950 \\
\hline Netherlands & 7.50 & 1.11 & 5.87 & 7.67 & 8.84 & 1301 \\
\hline Portugal & 8.86 & 0.91 & 7.60 & 8.92 & 10.12 & 4404 \\
\hline Spain & 7.93 & 1.65 & 5.64 & 8.52 & 9.41 & 6197 \\
\hline Euro Area & 7.32 & 2.27 & 4.24 & 7.94 & 9.33 & 58041 \\
\hline \multicolumn{7}{|c|}{ Number of stock market crashes experienced } \\
\hline Austria & 3.39 & 2.55 & 1 & 3 & 8 & 2380 \\
\hline Belgium & 4.96 & 1.49 & 3 & 5 & 7 & 2327 \\
\hline Finland & 6.75 & 2.17 & 4 & 6 & 10 & 10989 \\
\hline France & 7.82 & 2.49 & 5 & 7 & 12 & 15006 \\
\hline Germany & 5.62 & 1.98 & 3 & 6 & 8 & 3565 \\
\hline Greece & 10.19 & 2.69 & 8 & 9 & 14 & 2971 \\
\hline Italy & 10.97 & 2.49 & 8 & 11 & 14 & 7951 \\
\hline Luxembourg & 4.4 & 1.82 & 3 & 4 & 8 & 950 \\
\hline Netherlands & 5.06 & 1.31 & 3 & 5 & 7 & 1301 \\
\hline Portugal & 11.62 & 2.01 & 9 & 12 & 13 & 4404 \\
\hline Spain & 6.68 & 2.06 & 4 & 6 & 10 & 6197 \\
\hline Euro Area & 7.37 & 3.14 & 3 & 7 & 12 & 58041 \\
\hline
\end{tabular}

Note: The table shows summary statistics for experienced stock returns (calculated according to equations (1) and (2) with a $\lambda$ of 4.5), and for the number of experienced stock market crashes or prolonged downturns (defined as annual nominal returns below -20\%). Sources: Eurosystem Household Finance and Consumption Survey, own calculations. 
Table 3: Correlations between nominal stock market returns, 1930-2010

\begin{tabular}{|c|c|c|c|c|c|c|c|c|c|c|c|}
\hline & Austria & Belgium & Finland & France & Germany & Greece & Italy & Luxembourg & Netherlands & Portugal & Spain \\
\hline Austria & 1.00 & 0.42 & 0.11 & 0.44 & 0.44 & 0.42 & 0.46 & 0.40 & 0.36 & 0.10 & 0.39 \\
\hline Belgium & & 1.00 & 0.42 & 0.58 & 0.47 & 0.18 & 0.46 & 0.75 & 0.57 & 0.14 & 0.49 \\
\hline Finland & & & 1.00 & 0.34 & 0.32 & -0.05 & 0.12 & 0.50 & 0.39 & 0.17 & 0.40 \\
\hline France & & & & 1.00 & 0.36 & 0.25 & 0.44 & 0.47 & 0.52 & 0.05 & 0.46 \\
\hline Germany & & & & & 1.00 & 0.03 & 0.30 & 0.46 & 0.60 & 0.08 & 0.27 \\
\hline Greece & & & & & & 1.00 & 0.39 & -0.08 & -0.06 & 0.02 & 0.28 \\
\hline Italy & & & & & & & 1.00 & 0.38 & 0.33 & 0.24 & 0.45 \\
\hline Luxembourg & & & & & & & & 1.00 & 0.51 & 0.25 & 0.37 \\
\hline Netherlands & & & & & & & & & 1.00 & 0.13 & 0.37 \\
\hline Portugal & & & & & & & & & & 1.00 & 0.28 \\
\hline Spain & & & & & & & & & & & 1.00 \\
\hline
\end{tabular}

Note: The table shows correlations between annual national nominal stock market returns, 1930-2010. 
Table 4: The effect of experienced stock market returns on households' willingness to take financial risks

\begin{tabular}{|c|c|c|c|c|c|c|c|c|c|c|c|}
\hline & Coefficien & & Std. error & $\begin{array}{c}\text { AME } \\
\text { Willingness=1 }\end{array}$ & Std. error & $\begin{array}{c}\text { AME } \\
\text { Willingness=2 }\end{array}$ & Std. error & $\begin{array}{c}\text { AME } \\
\text { Willingness=3 }\end{array}$ & Std. error & $\begin{array}{c}\text { AME } \\
\text { Willingness }=4\end{array}$ & Std. error \\
\hline Weighting parameter $(\lambda)$ & 3.860 & $* * *$ & 0.569 & -- & -- & -- & -- & -- & -- & -- & -- \\
\hline Experienced return $(\beta)$ & 4.637 & $* * *$ & 1.463 & $-0.014 * * *$ & 0.005 & $0.010 * * *$ & 0.003 & $0.004 * * *$ & 0.001 & $0.001 * * *$ & 0.000 \\
\hline Log income & -0.186 & $* *$ & 0.092 & $-0.025 * * *$ & 0.008 & $0.015^{* * *}$ & 0.005 & $0.008 * * *$ & 0.002 & $0.002 * * *$ & 0.001 \\
\hline Log income squared & 0.013 & $* * *$ & 0.005 & -- & -- & -- & -- & -- & -- & -- & -- \\
\hline Number of children & -0.013 & & 0.039 & 0.004 & 0.009 & -0.003 & 0.006 & -0.001 & 0.002 & 0.000 & 0.001 \\
\hline Number of children squared & 0.000 & & 0.013 & -- & -- & -- & -- & -- & -- & -- & -- \\
\hline Log liquid assets & -0.119 & $* * *$ & 0.015 & $-0.032 * * *$ & 0.003 & $0.019 * * *$ & 0.002 & $0.011 * * *$ & 0.001 & $0.003 * * *$ & 0.000 \\
\hline Log liquid assets squared & 0.013 & $* * *$ & 0.001 & -- & -- & -- & -- & -- & -- & -- & -- \\
\hline Retired & -0.099 & $* *$ & 0.043 & $0.031 * *$ & 0.013 & $-0.020 * *$ & 0.009 & $-0.009 * *$ & 0.004 & $0.002 * *$ & 0.001 \\
\hline College & 0.314 & $* * *$ & 0.043 & $-0.098 * * *$ & 0.014 & $0.062 * * *$ & 0.009 & $0.030 * * *$ & 0.004 & $0.006 * * *$ & 0.001 \\
\hline High school & 0.192 & $* * *$ & 0.038 & $-0.060 * * *$ & 0.012 & $0.038 * * *$ & 0.008 & $0.018 * * *$ & 0.004 & $0.004 * * *$ & 0.001 \\
\hline Age & -0.020 & $* *$ & 0.008 & $0.005 * * *$ & 0.001 & $-0.003 * * *$ & 0.000 & $-0.001 * * *$ & 0.000 & $0.000 * * *$ & 0.000 \\
\hline Age squared & 0.000 & & 0.000 & -- & -- & -- & -- & -- & -- & -- & -- \\
\hline Married & -0.086 & $* *$ & 0.034 & $0.027 * *$ & 0.011 & $-0.017 * *$ & 0.007 & $-0.008 * *$ & 0.003 & $-0.002 * *$ & 0.001 \\
\hline Financial sector employee & 0.238 & $* * *$ & 0.056 & $-0.075 * * *$ & 0.018 & $0.048 * * *$ & 0.011 & $0.023 * * *$ & 0.005 & $0.005 * * *$ & 0.001 \\
\hline Male & 0.238 & $* * *$ & 0.030 & $-0.075 * * *$ & 0.009 & $0.047^{* * *}$ & 0.006 & $0.022 * * *$ & 0.003 & $0.005 * * *$ & 0.001 \\
\hline Austria & 0.051 & & 0.058 & -0.016 & 0.018 & 0.010 & 0.012 & 0.005 & 0.005 & 0.001 & 0.001 \\
\hline Belgium & -0.207 & $* * *$ & 0.052 & $0.065 * * *$ & 0.016 & $-0.041 * * *$ & 0.010 & $-0.019 * * *$ & 0.005 & $-0.004 * * *$ & 0.001 \\
\hline Greece & -0.061 & & 0.075 & 0.017 & 0.016 & -0.011 & 0.010 & -0.005 & 0.005 & -0.001 & 0.001 \\
\hline Italy & 0.914 & $* * *$ & 0.073 & $-0.287 * * *$ & 0.022 & $0.182 * * *$ & 0.014 & $0.086 * * *$ & 0.007 & $0.018 * * *$ & 0.002 \\
\hline Luxembourg & -0.590 & $* * *$ & 0.071 & $0.184 * * *$ & 0.023 & $-0.117 * * *$ & 0.014 & $-0.056 * * *$ & 0.007 & $-0.012 * * *$ & 0.002 \\
\hline Netherlands & -0.239 & $* * *$ & 0.058 & $0.074^{* * *}$ & 0.018 & $-0.047 * * *$ & 0.011 & $-0.022 * * *$ & 0.005 & $-0.005 * * *$ & 0.001 \\
\hline Portugal & -0.763 & $* * *$ & 0.056 & $0.239 * * *$ & 0.018 & $-0.152 * * *$ & 0.011 & $-0.072 * * *$ & 0.006 & $-0.015 * * *$ & 0.002 \\
\hline Spain & -0.438 & $* * *$ & 0.050 & $0.136 * * *$ & 0.015 & $-0.087 * * *$ & 0.010 & $-0.041 * * *$ & 0.005 & $-0.009 * * *$ & 0.001 \\
\hline \multicolumn{12}{|l|}{ Fitted probabilities at p90-p10 } \\
\hline Willingness $=1$ (low) & -0.067 & $* * *$ & 0.002 & -- & -- & -- & -- & -- & -- & -- & -- \\
\hline Willingness=2 & 0.042 & $* * *$ & 0.001 & -- & -- & -- & -- & -- & -- & -- & -- \\
\hline Willingness $=3$ & 0.020 & $* * *$ & 0.001 & -- & -- & -- & -- & -- & -- & -- & -- \\
\hline Willingness $=4$ (high) & 0.005 & $* * *$ & 0.000 & -- & -- & -- & -- & -- & -- & -- & -- \\
\hline Cutoff point 1 & -0.271 & -- & 0.478 & $\overline{--}$ & $\overline{--}$ & -- & $\overline{--}$ & $\overline{--}$ & -- & -- & -- \\
\hline Cutoff point 2 & 0.949 & -- & 0.479 & -- & -- & -- & -- & -- & -- & -- & -- \\
\hline Cutoff point 3 & 1.985 & -- & 0.482 & -- & -- & -- & -- & -- & -- & -- & -- \\
\hline Pseudo R squared & & & & & & 0.11 & & & & & \\
\hline
\end{tabular}

Note: The table shows estimated coefficients of the ordered probit model according to equation (3), explaining households' willingness to take financial risks, as well as average marginal effects (AME) for each category of the ordered probit. For the effect of experienced returns $(\beta)$, the table also reports the average of the fitted probability at the 90th percentile minus the average fitted probability at the 10th percentile of the distribution of experienced returns, for each category of the ordered probit. 
Table 5: The effect of experienced stock market returns on stock market participation

\begin{tabular}{|c|c|c|c|c|}
\hline & Coefficient & Std. error & AME & Std. error \\
\hline Weighting parameter $(\lambda)$ & $5.244 * * *$ & 0.848 & -- & -- \\
\hline Experienced return $(\beta)$ & $15.176 * * *$ & 3.104 & $0.022 * * *$ & 0.004 \\
\hline Log income & -0.168 & 0.289 & $0.021 * * *$ & 0.005 \\
\hline Log income squared & 0.015 & 0.014 & -- & -- \\
\hline Number of children & 0.001 & 0.043 & 0.000 & 0.005 \\
\hline Number of children squared & -0.003 & 0.013 & -- & -- \\
\hline Log liquid assets & $0.301 * *$ & 0.123 & $0.066 * * *$ & 0.002 \\
\hline Log liquid assets squared & 0.007 & 0.006 & -- & -- \\
\hline Retired & -0.061 & 0.054 & -0.009 & 0.008 \\
\hline College & $0.390 * * *$ & 0.049 & $0.057 * * *$ & 0.007 \\
\hline High school & $0.199 * * *$ & 0.044 & $0.029 * * *$ & 0.007 \\
\hline Age & 0.006 & 0.012 & $-0.002 * * *$ & 0.000 \\
\hline Age squared & 0.000 & 0.000 & -- & -- \\
\hline Married & -0.061 & 0.041 & -0.009 & 0.006 \\
\hline Financial sector employee & $0.662 * * *$ & 0.080 & $0.097 * * *$ & 0.011 \\
\hline Male & $0.165 * * *$ & 0.037 & $0.024 * * *$ & 0.005 \\
\hline Austria & $-0.991 * * *$ & 0.110 & $-0.146 * * *$ & 0.016 \\
\hline Belgium & $0.195 * *$ & 0.084 & $0.029 * *$ & 0.011 \\
\hline Finland & -0.209 & 0.247 & -0.030 & 0.021 \\
\hline France & $0.307 * * *$ & 0.069 & $0.045 * * *$ & 0.007 \\
\hline Greece & $-0.463 * *$ & 0.230 & $-0.067 * * *$ & 0.014 \\
\hline Italy & 0.183 & 0.136 & 0.027 & 0.020 \\
\hline Luxembourg & $-0.750 * * *$ & 0.117 & $-0.110 * * *$ & 0.016 \\
\hline Netherlands & 0.063 & 0.095 & 0.009 & 0.012 \\
\hline Portugal & $-0.380 * * *$ & 0.085 & $-0.056 * * *$ & 0.011 \\
\hline Spain & 0.110 & 0.116 & $0.017 *$ & 0.010 \\
\hline Fitted probabilities at $p 90-p 10$ & $0.113^{* * *}$ & 0.003 & -- & -- \\
\hline Pseudo R squared & \multicolumn{4}{|c|}{0.31} \\
\hline
\end{tabular}

Note: The table shows estimated coefficients of the probit model according to equation (3), explaining households' participation in stock markets, as well as average marginal effects (AME). For the effect of experienced returns $(\beta)$, the table also reports the average of the fitted probability at the 90th percentile minus the average fitted probability at the 10th percentile of the distribution of experienced returns. 
Table 6: The effect of experienced stock market returns on the share of stocks in liquid assets

\begin{tabular}{lcc}
\hline \hline & Coefficient & Std. error \\
\hline Weighting parameter $(\lambda)$ & $7.558^{* * *}$ & 0.799 \\
Experienced return $(\beta)$ & $3.772 * * *$ & 1.048 \\
Log income & 0.020 & 0.202 \\
Log income squared & 0.003 & 0.009 \\
Number of children & -0.010 & 0.019 \\
Number of children squared & 0.003 & 0.006 \\
Log liquid assets & $0.232 * * *$ & 0.057 \\
Log liquid assets squared & -0.002 & 0.003 \\
Retired & -0.015 & 0.024 \\
College & $0.188 * * *$ & 0.026 \\
High school & $0.131 * * *$ & 0.024 \\
Age & $0.011^{* *}$ & 0.005 \\
Age squared & $0.000 * * *$ & 0.000 \\
Married & -0.027 & 0.019 \\
Financial sector employee & $0.260 * * *$ & 0.034 \\
Male & $0.082 * * *$ & 0.018 \\
Austria & $-0.343 * * *$ & 0.051 \\
Belgium & $0.130 * * *$ & 0.042 \\
Finland & $0.278 * * *$ & 0.052 \\
France & $0.266 * * *$ & 0.031 \\
Greece & 0.064 & 0.069 \\
Italy & 0.083 & 0.071 \\
Luxembourg & $-0.251 * * *$ & 0.053 \\
Netherlands & 0.053 & 0.053 \\
Portugal & -0.026 & 0.037 \\
Spain & $0.256 * * *$ & 0.048 \\
\hline Fitted value at $p 90-p 10$ & $0.045 * * *$ & 0.002 \\
\hline Pseudo R squared & \multicolumn{2}{c}{0.28} \\
\hline \hline
\end{tabular}

Note: The table shows estimated coefficients of the Tobit model according to equation (3), explaining the share of stocks in liquid assets. For the effect of experienced returns $(\beta)$, the table also reports the average of the fitted probability at the 90th percentile minus the average fitted probability at the 10th percentile of the distribution of experienced returns. 
Table 7: The effect of experienced stock market returns on stock market participation; extensions and robustness tests

\begin{tabular}{|c|c|c|c|c|c|c|}
\hline & & \multicolumn{2}{|c|}{ Experienced return $(\beta)$} & \multicolumn{2}{|c|}{ Weighting parameter $(\lambda)$} & \multirow{2}{*}{$\begin{array}{l}\text { Pseudo R- } \\
\text { squared }\end{array}$} \\
\hline & & Coefficient & Std. error & Coefficient & Std. error & \\
\hline$\overline{(1)}$ & Benchmark model & $15.18^{* * *}$ & 3.10 & $5.24 * * *$ & 0.85 & 0.31 \\
\hline$(2)$ & Explaining bond holdings with bond returns & $27.78 *$ & 14.92 & $3.99 * * *$ & 0.33 & 0.36 \\
\hline (3) & Adding experienced volatility & $16.77^{* * *}$ & 2.91 & $5.01 * * *$ & 0.26 & 0.31 \\
\hline (4) & Stock holdings include voluntary pension plans & $15.54 * * *$ & 2.67 & $5.11 * * *$ & 0.24 & 0.24 \\
\hline (5) & Unweighted estimation & $4.72 * * *$ & 0.79 & $9.80 * * *$ & 0.73 & 0.34 \\
\hline (6) & Adding experienced bond returns & $10.71 * * *$ & 2.35 & $6.03 * * *$ & 0.32 & 0.31 \\
\hline (7) & Longer experience horizon (10 years before birth) & $10.50 * * *$ & 2.01 & $3.81 * * *$ & 0.48 & 0.31 \\
\hline (8) & Shorter experience horizon (10 years after birth) & $21.03 * * *$ & 3.72 & $6.41 * * *$ & 0.42 & 0.31 \\
\hline (9) & Adding risk aversion & $12.86 * * *$ & 2.82 & $5.84 * * *$ & 0.45 & 0.35 \\
\hline (10) & Adding real assets & $15.23 * * *$ & 2.67 & $5.24 * * *$ & 0.21 & 0.35 \\
\hline (11) & Adding year-of-birth dummies & $11.50 * * *$ & 3.19 & $4.02 * * *$ & 0.25 & 0.32 \\
\hline (12) & Excluding immigrants & $6.74 * * *$ & 0.95 & $9.97 * * *$ & 0.90 & 0.33 \\
\hline (13) & Clustered errors by country & $15.18 * * *$ & 4.22 & $5.24 * * *$ & 0.30 & 0.31 \\
\hline (14) & Placebo experiment & 0.07 & 1.10 & 5.24 & [fixed] & 0.31 \\
\hline (15) & Countries with a less severe 2008 stock market crash & $15.60 * * *$ & 3.63 & $5.47 * * *$ & 0.25 & 0.29 \\
\hline (16) & Countries with a very severe 2008 stock market crash & 1.48 & 1.56 & $10.77 * * *$ & 1.13 & 0.34 \\
\hline
\end{tabular}

Note: The table shows estimated coefficients $\beta$ and $\lambda$ of the probit model according to equation (3). Row (1) repeats the benchmark results, explaining households' participation in stock markets. Row (2) explains participation in bond markets as a function of experienced bond returns. Rows (3) to (13) explain participation in stock markets. Row (3) adds the experienced stock market volatility. Row (4) is based on a broader definition of stockholdings, also including investments in voluntary pension plans. Row (5) provides unweighted results. Row (6) additionally includes the bond returns that households have experienced over their lifetimes. Rows (7) and (8) vary the experience horizon of respondents, by either including 10 years prior to birth, or by starting 10 years after birth. Row (9) adds households' willingness to take financial risks as additional regressor. Row (10) adds the level of real asset holdings. Row (11) adds year-of-birth dummies. Row (12) excludes immigrants from the estimation. Row (13) clusters standard errors by country. Row (14) reports results from a placebo experiment. Rows (15) and (16) contain split sample estimates, once for countries with less-severe stock market crashes in 2008 , and once for the very severely hit countries. 
Table 8: The effect of stock market downturns on households' willingness to take financial risks

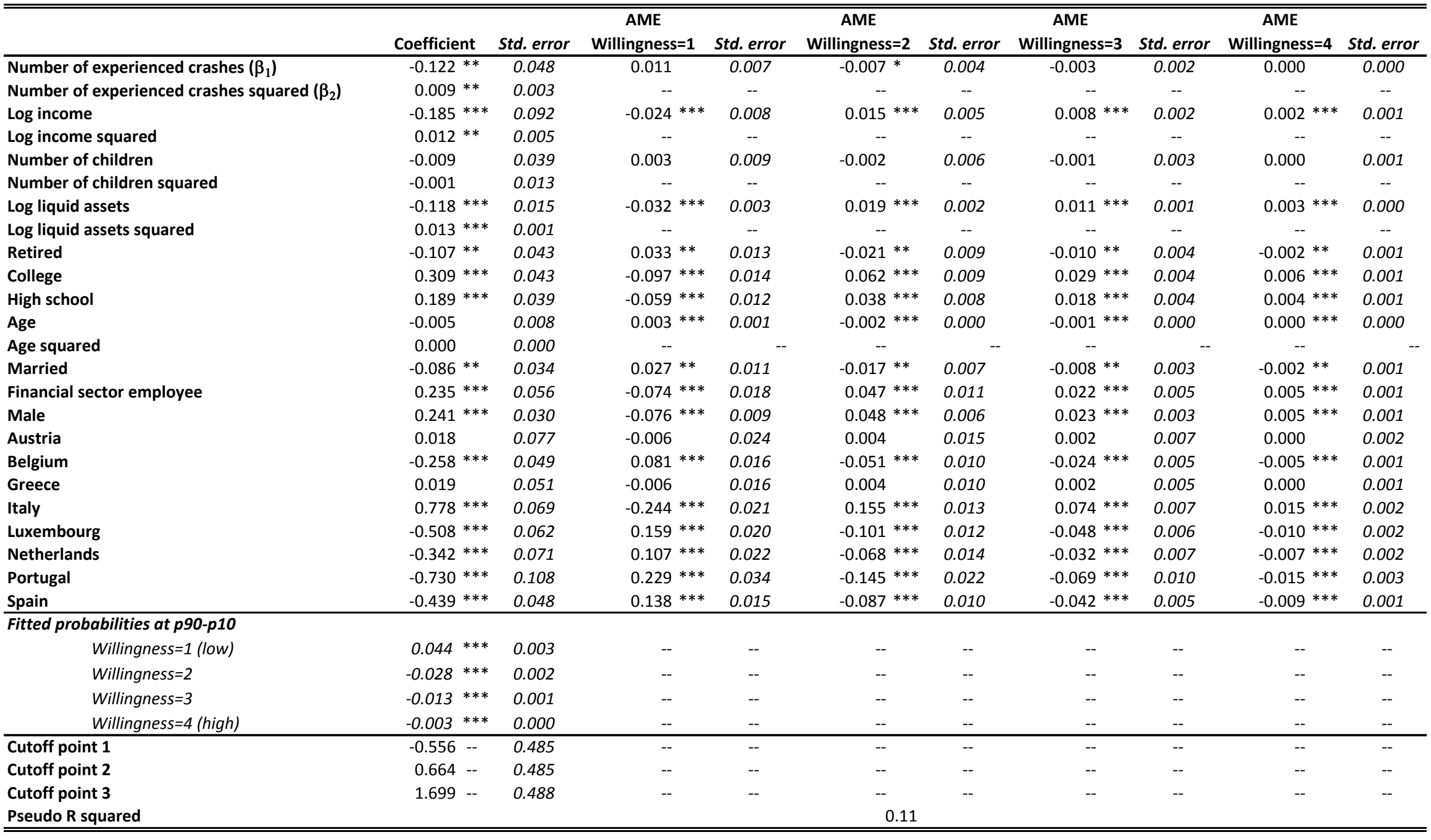

Note: The table shows estimated coefficients of the ordered probit model according to equation (4), explaining households' willingness to take financial risks, as well as average marginal effects (AME) for each category of the ordered probit. For the effect of experienced crashes $\left(\beta_{1}\right.$ and $\left.\beta_{2}\right)$, the table also reports the average of the fitted probability at the 90th percentile minus the average fitted probability at the 10th percentile of the distribution of experienced crashes, for each category of the ordered probit. 
Table 9: The effect of experienced stock market downturns on stock market participation

\begin{tabular}{|c|c|c|c|c|}
\hline & Coefficient & Std. error & AME & Std. error \\
\hline Number of experienced crashes $\left(\beta_{1}\right)$ & $-0.316^{* * *}$ & 0.071 & $-0.020 * * *$ & 0.004 \\
\hline Number of experienced crashes squared $\left(\beta_{2}\right)$ & $0.019 * * *$ & 0.005 & -- & -- \\
\hline Log income & -0.183 & 0.259 & 0.020 & 0.005 \\
\hline Log income squared & 0.015 & 0.012 & -- & -- \\
\hline Number of children & 0.002 & 0.043 & 0.000 & 0.005 \\
\hline Number of children squared & -0.002 & 0.012 & -- & -- \\
\hline Log liquid assets & $0.293 * *$ & 0.122 & $0.067 * * *$ & 0.002 \\
\hline Log liquid assets squared & 0.008 & 0.006 & -- & -- \\
\hline Retired & $-0.091 *$ & 0.055 & -0.013 & 0.008 \\
\hline College & $0.377 * * *$ & 0.047 & $0.056 * * *$ & 0.007 \\
\hline High school & $0.187^{* * *}$ & 0.043 & $0.028 * * *$ & 0.006 \\
\hline Age & $0.042 * * *$ & 0.009 & $0.001 * * *$ & 0.000 \\
\hline Age squared & $0.000 * * *$ & 0.000 & -- & -- \\
\hline Married & -0.065 & 0.041 & -0.010 & 0.006 \\
\hline Financial sector employee & $0.657 * * *$ & 0.080 & $0.097 * * *$ & 0.012 \\
\hline Male & $0.174 * * *$ & 0.038 & $0.026 * * *$ & 0.006 \\
\hline Austria & $-1.008 * * *$ & 0.124 & $-0.149 * * *$ & 0.019 \\
\hline Belgium & -0.046 & 0.069 & -0.007 & 0.010 \\
\hline Finland & $0.476 * * *$ & 0.049 & $0.070 * * *$ & 0.007 \\
\hline France & $0.251 * * *$ & 0.047 & $0.037 * * *$ & 0.007 \\
\hline Greece & $-0.395 * * *$ & 0.086 & $-0.058 * * *$ & 0.013 \\
\hline Italy & $-0.308 * * *$ & 0.087 & $-0.045 * * *$ & 0.013 \\
\hline Luxembourg & $-0.485 * * *$ & 0.083 & $-0.072 * * *$ & 0.013 \\
\hline Netherlands & $-0.342 * * *$ & 0.105 & $-0.051 * * *$ & 0.016 \\
\hline Portugal & -0.139 & 0.140 & -0.020 & 0.021 \\
\hline Spain & -0.012 & 0.064 & -0.002 & 0.009 \\
\hline Fitted probabilities at p90-p10 & $-0.091^{* * *}$ & 0.001 & -- & -- \\
\hline Pseudo R squared & \multicolumn{4}{|c|}{0.31} \\
\hline
\end{tabular}

Note: The table shows estimated coefficients of the probit model according to equation (4), explaining households' participation in stock markets, as well as average marginal effects (AME). For the effect of experienced crashes $\left(\beta_{1}\right.$ and $\left.\beta_{2}\right)$, the table also reports the fitted probability at the 90th percentile minus the average fitted probability at the 10th percentile of the distribution of experienced returns. 
Table 10: The effect of experienced stock market downturns on the share of stocks in liquid assets

\begin{tabular}{lcc}
\hline \hline & Coefficient & Std. error \\
\hline Number of experienced crashes $\left(\boldsymbol{\beta}_{1}\right)$ & -0.034 & 0.029 \\
Number of experienced crashes squared $\left(\boldsymbol{\beta}_{2}\right)$ & 0.002 & 0.002 \\
Log income & -0.203 & 0.153 \\
Log income squared & 0.009 & 0.007 \\
Number of children & -0.011 & 0.016 \\
Number of children squared & 0.004 & 0.004 \\
Log liquid assets & $-0.172 * * *$ & 0.056 \\
Log liquid assets squared & $0.007 * * *$ & 0.003 \\
Retired & $0.044 * *$ & 0.021 \\
College & 0.026 & 0.020 \\
High school & 0.006 & 0.018 \\
Age & 0.006 & 0.004 \\
Age squared & 0.000 & 0.000 \\
Married & 0.002 & 0.014 \\
Financial sector employee & 0.013 & 0.020 \\
Male & -0.003 & 0.015 \\
Austria & 0.006 & 0.061 \\
Belgium & $0.057 * *$ & 0.023 \\
Finland & $0.079 * * *$ & 0.019 \\
France & $0.091 * * *$ & 0.017 \\
Greece & $0.122 * *$ & 0.048 \\
Italy & $0.112 * *$ & 0.038 \\
Luxembourg & $0.097 * *$ & 0.039 \\
Netherlands & -0.025 & 0.047 \\
Portugal & 0.030 & 0.072 \\
Spain & $0.081 * * *$ & 0.025 \\
\hline Fitted value at $p 90-p 10$ & $-0.012 * * *$ & 0.002 \\
\hline \hline & & \\
\hline \hline
\end{tabular}

Note: The table shows estimated coefficients of the Tobit model according to equation (4), explaining the share of stocks in liquid assets. For the effect of experienced crashes $\left(\beta_{1}\right.$ and $\left.\beta_{2}\right)$, the table also reports the average of the fitted probability at the 90th percentile minus the average fitted probability at the 10th percentile of the distribution of experienced returns. 
Table 11: The effect of experienced stock market crashes on stock market participation; extensions and robustness tests

\begin{tabular}{llcc}
\hline \hline & Coefficient & Std. error & $\begin{array}{c}\text { Pseudo R } \\
\text { squared }\end{array}$ \\
\hline (1) Benchmark model & & & 0.31 \\
(2) Adding experienced stock returns & $-0.020^{* * *}$ & 0.004 & 0.31 \\
(3) Adding the number of experienced booms & $-0.011^{* *}$ & 0.004 & 0.31 \\
(4) Crashes defined as below -40\% annual returns & $-0.018^{* * *}$ & 0.004 & 0.31 \\
(5) Stock holdings include voluntary pension plans & $-0.062 * * *$ & 0.012 & $0.075^{* * *}$ \\
(6) Unweighted estimation & -0.003 & 0.006 & 0.002 \\
(7) Adding risk aversion & $-0.014 * * *$ & 0.005 & 0.34 \\
(8) Adding real assets & $-0.020 * * *$ & 0.004 & 0.31 \\
(9) Adding year-of-birth dummies & $-0.013 * * *$ & 0.004 & 0.32 \\
(10) Excluding immigrants & -0.009 & 0.007 & 0.36 \\
(11) Clustered errors by country & $-0.020 *$ & 0.010 & 0.31 \\
(12) Placebo experiment & -0.000 & 0.004 & 0.31 \\
\hline \hline
\end{tabular}

Note: The table shows estimated average marginal effects of the experienced stock market crashes on participation in stock markets, based on the probit model according to equation (4). Row (1) repeats the benchmark results. Row (2) adds the experienced stock market returns. Row (3) adds stock market booms. Row (4) changes the definition of a downturn to cases where annual nominal stock returns were below - $40 \%$. Row (5) includes voluntary pension plans in the definition of stockholdings. Row (6) provides unweighted results. Row (7) adds households' willingness to take financial risks. Row (8) adds the level of real asset holdings. Row (9) adds year-of-birth dummies. Row (10) reports results for an estimation that excludes immigrants. Row (11) clusters standard errors by country. Row (12) shows the results for a placebo experiment where the number of experienced crises has been assigned randomly across the distribution of households. 